\title{
Comparisom of perceived chromatic differences with colorimetric colour-differences for colour chips with constant value and hue
}

\begin{abstract}
Masaharu NAKAYAMA*, Koichi IKEDA* and Kiyoshige OBARA*
In order to study the perceptual scaling of chroma, perceived chroma-differences of colour chips are subjectively estimated by means of ratio estimation method under standard illuminant $A$ and daylight $D_{65}$.

The subjectively estimated values are compared with their colorimetric colour-differences in the CIE $1976 L^{*} u^{*} v^{*}$ and $L^{*} a^{*} b^{*}$ uniform colour spaces.

The set of colour chips used in the experiment consists of eight hues (5R, 5YR, 5Y, 7.5GY, 3.5G, 10BG, 2.5PB and 5RP) with constant vlue 6, and chromas are from 0.3 to 13.7 at intervals of about 0.5 in the Munsell renotation system.

Results obtained are summarized as follows:

(1) Relative values of perceived colour-differences change little even when the illuminant is changed from the daylight $D_{65}$ to the illuminant $A$, and the constancy of perceived colour-difference holds as well as in the case of hue-difference.

(2) Colorimetric chroma-differences in the $L^{*} u^{*} v^{*}$ and $L^{*} a^{*} b^{*}$ spaces generally do not change much when the illuminant is changed.

But, because of the insufficient compensation for chromatic adaptation, those for colours of $3.5 \mathrm{G}$ in both spaces change slightly.

(3) Except for colours of $5 \mathrm{Y}$ and 3.5G, relative values of perceived colour-differences to colorimetric ones tend to become small generally with the increase in saturation.

(4) For colours of $5 \mathrm{Y}$ and $7.5 \mathrm{GY}$, the correlation between perceived colour-differences and colorimetric ones is slightly low in both colour spaces irrespective of the illuminant.
\end{abstract}

\section{Introduction}

The psychophysically measured quantities can be used conveniently for precise and simple specification of colours, but they may not always represent the correct appearance of colours.

It is desirable, in principle, that there is one to one correspondence between the psychophysical quantities and the perceived ones. From this point of view, the CIE recommended two uniform colour spaces, $1976 \mathrm{~L}^{*} \mathrm{u}^{*} \mathrm{v}^{*}$ and 1976 $\mathrm{L} * \mathrm{a} * \mathrm{~b} *(1)$. This recommendation was issued provisionally on the grounds that the former space was superior to others in evaluation of small colour-differences and light-source colours

\footnotetext{
* Faculty of Science and Technology, Tokyo Rika Daigaku

2641 Yamazaki, Noda 278 Japan

This study was previously published in $\mathrm{J}$. Illum. Engng. Inst. Jpn. 70-2 (1986).
}

while the latter in that of large colour-differences and object colours; however, there has been an insufficient correspondence to the perceived quantities in either space. Therefore, development of a better colour space will require studies of a large body of data from visual experiments conducted under various conditions.

Ikeda and co-workers have studied the correspondence between the perceived colourdifferences and the colorimetric ones for different hues using colour chips which are constant in lightness and chroma and different only in hue $(2) \sim(6)$.

The present study is a continuation of the above studies with the objectives of investigating the chroma-differences and scaling the chroma. In its first phase, an investigation was carried out on the relation between the perceived chroma-differences and the colorimetric ones in two uniform colour spaces, CIE 1976 $\mathrm{L}^{*} \mathrm{u}^{*} \mathrm{v} *$ and CIE $1976 \mathrm{~L} \mathrm{a}^{*} \mathrm{~b} *$, for 8 hues (red, 
yellowish red, yellow, yellowish green, green, bluish green, blue, and purple).

Many researchers have conducted visual experiments on colour-differences under the conditions they chose, which makes comparison of their results difficult. To overcome this difficulty, all the experiments in the present study were carried out under the same conditions as Ikeda and co-workers used in their earlier works.

\section{Colour chips used for the estimation of chroma-differences}

Colour chips constant in lightness and hue and different only in chroma were used in the estimation of colour-differences. The colour chips were designed in the following manner. First, the lightness was fixed at Value 6 in order to facilitate comparison of the present study with earlier ones by Ikeda and co-workers on the colour-differences. Second, 8 hues were chosen; four principal hues (red, yellow, green, and blue) and four intermediate hues (yellowish red, yellowish green, bluish green, and purple). In practice, those hues which look as much like the 8 hues as possible were subjectively chosen from JIS Standard Color Atlas.

The hues thus chosen were $5 \mathrm{R}, 5 \mathrm{Y}, 3.5 \mathrm{G}$, 2.5PB, 5YR, 7.5GY, 10BG, and 5RP in the Munsell renotation system. The chroma was made to vary at constant intervals of 0.5 up to the upper limit or the maximum chroma that could be prepared. The colour chips designed as above were prepared by the Japan Color Research Institute. All the colour chips were each measured for the spectral reflectance three times with the aid of a Hitachi Model 139 spectrophotometer and the averages were used in the clculation of chromaticity, etc.

Fig. 1 (a) shows the H-C coordinates in the Munsell renotation space for all the colour chips. Figs. 1 (b) and 1 (c) show the coordinates in the CIE $1976 \mathrm{~L}^{*} \mathrm{u} * \mathrm{v}^{*}$ uniform colour space and the CIE $1976 \mathrm{~L}^{*} \mathrm{a} \mathrm{b}^{*}$ uniform colour space respectively, each under the daylight $D_{65}$ and the standard illuminant $\mathrm{A}$.

The colour-differences for different chromas in the visual experiments were evaluated for each and the pairs of colour chips to be given observers were prepared as follows.

A pair of colour chips as standard in the

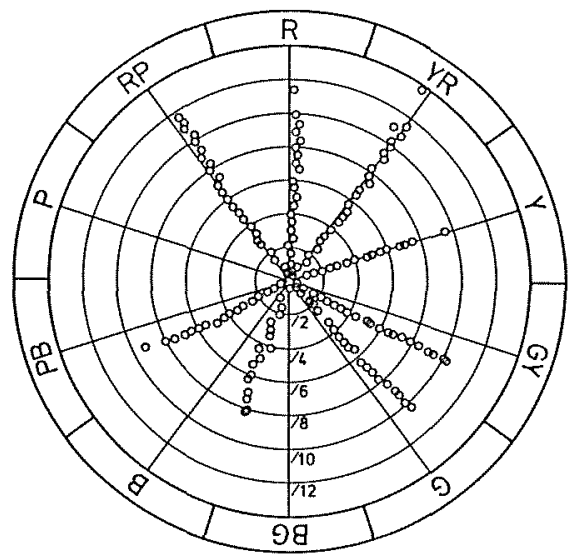

(a)

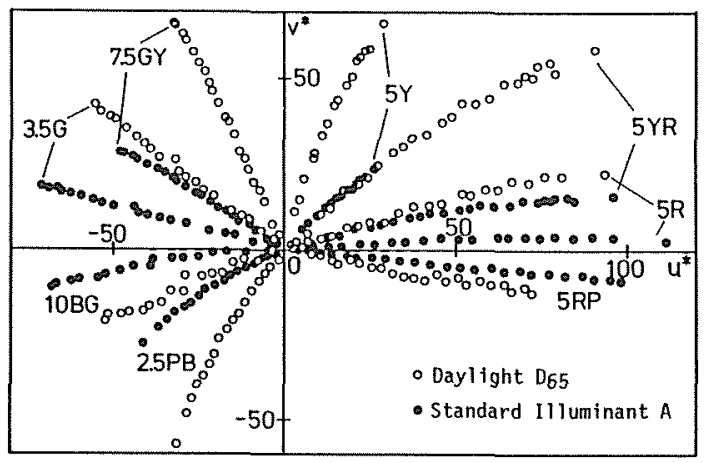

(b)

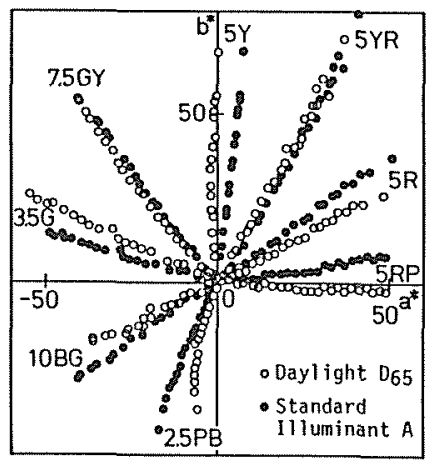

(c)

Fig. 1 Coordinates of colour chips in each colorimetric space.
(a) Munsell renotation system
(b) CIE $L * u^{*} v^{*}$ space
(c) CIE $L * a * b *$ space

estimation of colour-differences and 32 to 41 comparison pairs for each hue were chosen from a group of colour chips differing only in chroma using a table of random numbers. The standard pair was such that it gave $\Delta E_{a b}^{*}\left(\mathrm{D}_{65}\right)$, or colour-difference in the $\mathrm{L}^{*} \mathrm{a} * \mathrm{~b} *$ space under the daylight $\mathrm{D}_{65}$, of approximately 2 and was located roughly in the middle of the range of chromas prepared. The comparison pairs showed colour-differences ranging from nearly 
equal to 10 times those of the standard, or from 1.69 to 34.2 in $\Delta E^{*}{ }_{a b}\left(\mathrm{D}_{65}\right)$, with many of them distributed in the middle of this range.

Fig. 2 shows the combinations of the pairs of colour chips prepared and the colorimetric colour-differences for $3.5 \mathrm{G}$ as an example. In this figure, the colour chips are arranged in the order corresponding to the magnitude of chroma. The ends of each line segment correspond to the colour chip number and chroma and the number marked on the line segment indicates the colour-differences of the pair under the daylight $\mathrm{D}_{65}$ in the $\mathrm{L}^{*} \mathrm{u}^{*} \mathrm{v}^{*}$ space.

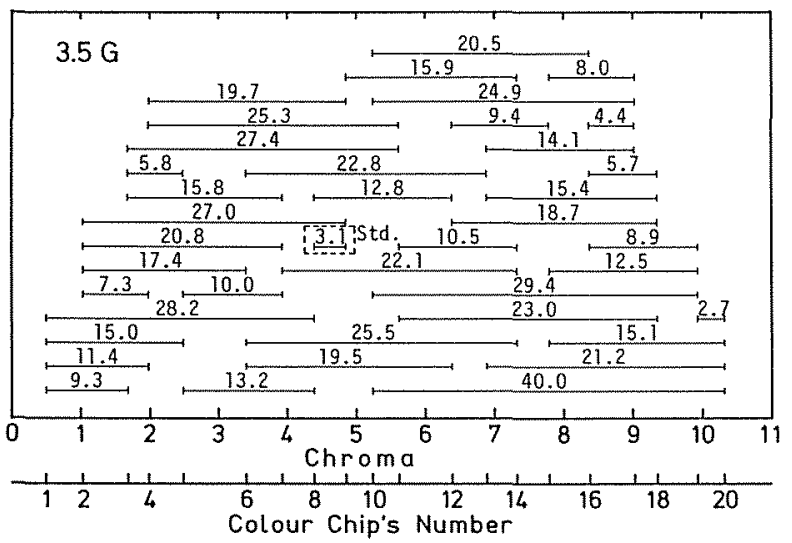

Fig. 2 Colorimetric colour-differences under the daylight $D_{65}$ in the $L^{*} u^{*} v^{*}$ space for every pair of colour chips (in the colours of $3.5 G)$.

Table 1 gives the kinds of all the colour chips used and the values and ranges of colorimetric colour-differences of the colour chips under the daylight $\mathrm{D}_{65}$ in the $\mathrm{L} * \mathrm{a} * \mathrm{~b} *$ space.

Each colour chip is $9 \mathrm{~mm}$ by $9 \mathrm{~mm}$ and subtends approximately $2.4^{\circ}$ of visual angle. Two chips are paired in contact alongside and are pasted on achromatic paper board having a lightness (V) of approximately 6. The standard pair is fixed to the colour chip plate whereas the comparison pair is exchangeable. The standard and comparison pairs set in place are $4 \mathrm{~mm}$ apart from each other as shown in Fig. 3 (b).

\section{Evaluation of the chroma-differences by the ratio estimation method}

The visual experiments were carried out with the application of the so-called ratio estimation method in which the ratios of the colourdifferences of two pairs of colour chips were used to evaluate the colour-differences.

The observers were instructed to compare the colour-differences of the test pair of colour chips with those of the standard pair, estimate the perceived ratio, multiply it by 10 , and report that number; for instance, if they find the ratio of the colour-differences somewhere between 2 and 2.5 , they should report that the ratio is 22 or 23 . They were also instructed to try to judge by intuition, not by deep thinking.

The colour chips covering the 8 hues were divided into two groups of 4 hues each and the visual experiments were carried out by group at different times. Therefore, the experiments are designated as Experiment I and Experiment II and their conditions are given in Table 2 .

In Experiment I, the CIE standard daylight $\mathrm{D}_{65}$ was simulated by a light generated by an apparatus for generating the illuminant with an arbitrary spectral energy distribution (7) shown in Fig. $3(a)$. The area illuminated by this simulated light on the colour chip plate was 25 times or more that of the test colour chip and was slightly more than $10^{\circ}$ in the visual angle

Table 1 The kinds of colour chips used in the visual experiments and the colorimetric colour-differences of those pair.

\begin{tabular}{|c|c|c|c|c|c|c|}
\hline \multicolumn{3}{|c|}{ Colour chip } & \multicolumn{2}{|c|}{ Standard pair } & \multicolumn{2}{|c|}{ Comparison pair } \\
\hline Hue & Range of chroma & Number & $\begin{array}{l}\text { Colour- } \\
\text { difference }\end{array}$ & $\begin{array}{l}\text { Mean } \\
\text { chroma }\end{array}$ & $\begin{array}{l}\text { Range of colour- } \\
\text { difference }\end{array}$ & Number \\
\hline $5 \mathrm{R}$ & $0.44-11.3$ & 21 & 2.57 & 4.7 & $2.73-24.5$ & 41 \\
\hline $5 Y$ & $0.27 \cdot 9.5$ & 17 & 3.11 & 3.8 & $4.02-34.2$ & 33 \\
\hline $3.5 \mathrm{G}$ & $0.50-10.3$ & 20 & 2.58 & 4.6 & $2.48-26.4$ & 39 \\
\hline $2.5 \mathrm{~PB}$ & $0.57-9.3$ & 17 & 1.76 & 4.2 & $3.31 \cdot 20.9$ & 33 \\
\hline $5 \mathrm{YR}$ & $0.53 \cdot 13.7$ & 25 & 2.50 & 6.6 & $1.98-27.6$ & 36 \\
\hline $7.5 \mathrm{GY}$ & $0.49-10.2$ & 21 & 2.49 & 6.7 & $2.11-29.0$ & 40 \\
\hline $10 \mathrm{BG}$ & $0.45-8.3$ & 17 & 2.01 & 3.3 & $1.93-21.0$ & 32 \\
\hline 5RP & $0.40-11.6$ & 24 & 1.97 & 6.7 & $1.69-19.0$ & 35 \\
\hline
\end{tabular}


Table 2 Conditions of the visual experiments

\begin{tabular}{|c|c|c|c|c|c|}
\hline \multirow{2}{*}{$\begin{array}{l}\text { Number } \\
\text { of } \\
\text { Experiment }\end{array}$} & \multirow{2}{*}{$\begin{array}{c}\text { Hue } \\
\text { of } \\
\text { Colour Chip }\end{array}$} & \multicolumn{2}{|c|}{ Condition of illumination } & \multirow{2}{*}{$\begin{array}{l}\text { Observer } \\
\text { (age) }\end{array}$} & \multirow{2}{*}{$\begin{array}{c}\text { Times } \\
\text { of } \\
\text { Estimation }\end{array}$} \\
\hline & & Daylight $D_{65}$ & Illuminant $\mathrm{A}$ & & \\
\hline I & $\begin{array}{l}5 \mathrm{R} \\
5 \mathrm{Y} \\
3.5 \mathrm{G} \\
2.5 \mathrm{~PB}\end{array}$ & $\begin{array}{l}\text { Simulated illuminant } \\
2501 \mathrm{x} \\
50 \mathrm{~cd} / \mathrm{m}^{2} * \\
\text { Background more than } 10^{\circ}\end{array}$ & $\begin{array}{l}\text { Incandescent lamp }(2856 \mathrm{~K}) \\
5001 \times \\
100 \mathrm{~cd} / \mathrm{m}^{2} * \\
\text { Background more than } 30^{\circ}\end{array}$ & $\begin{array}{l}\text { Two males } \\
(22,24) \\
\text { Normal colour } \\
\text { vision }\end{array}$ & $\begin{array}{l}15 \\
\text { (per } \\
\text { observer) }\end{array}$ \\
\hline II & $\begin{array}{l}5 \mathrm{YR} \\
7.5 \mathrm{GY} \\
10 \mathrm{BG} \\
5 \mathrm{RP}\end{array}$ & $\begin{array}{l}\text { Xenon lamp (direct light) } \\
400 \mathrm{xx} \\
100 \mathrm{~cd} / \mathrm{m}^{2} * \\
\text { Background more than } 30^{\circ}\end{array}$ & $\begin{array}{l}\text { Incandescent lamp (2856K) } \\
6001 \times \\
130 \mathrm{~cd} / \mathrm{m}^{2} * \\
\text { Background more than } 30^{\circ}\end{array}$ & $\begin{array}{l}\text { Four males } \\
(22,23,23,43) \\
\text { Normal colour } \\
\text { vision }\end{array}$ & $\begin{array}{l}\quad 3 \\
\text { (per } \\
\text { observer) }\end{array}$ \\
\hline
\end{tabular}

* The luminance of a white paper "Kent" set on the plane of the colour chips was measured under the condition of illumination and observation 45 /normal.

subtended by the illuminated area as shown in Fig. 3 (b). This practically satisfies the conditions recommended by the CIE for chromatic adaptation (8).

The standard illuminant $\mathrm{A}$ was generated by a $100 \mathrm{~V}, 100 \mathrm{~W}$ incandescent lamp whose colour temperature was regulated at $2856 \mathrm{~K}$ by control of the voltage. Fig. 3 (c) shows the experimental arrangement under this illuminant.

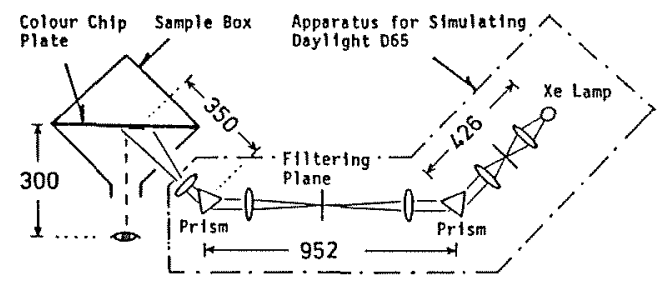

(a)
On the other hand, the illuminating conditions in Experiment II differ a little from those in Experiment I. As shown in Fig. 3 (d), the observation was made in a small observation booth, $1.5 \mathrm{~m}$ wide, $1.2 \mathrm{~m}$ deep, and $2.3 \mathrm{~m}$ high, under uniform illumination from light sources fixed on the ceiling. The daylight $D_{65}$ was provided by two $150 \mathrm{~W}$ short arc xenon lamps

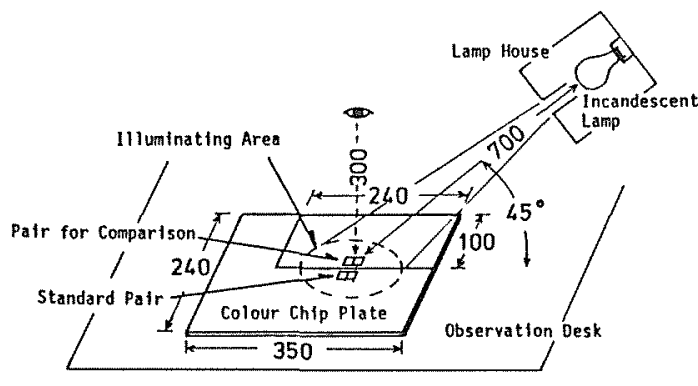

(c)

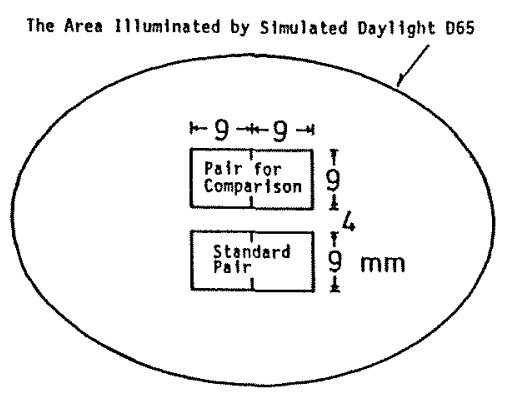

(b)

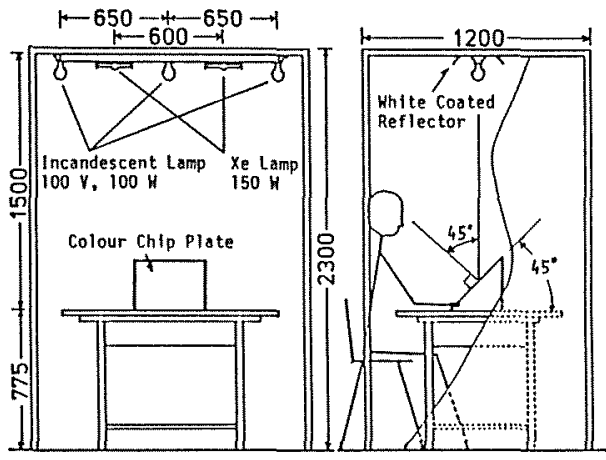

(d)

Fig. 3 Conditions of experiments to estimate perceived colour-differences.

(a) Experiment under the daylight $D_{65}$ (Exp. I).

(b) Dispositions of the standard pair and test pair of colour chips. (c) Experiment under the standard illuminant $A$ (Exp. I)

(d) Booth for experiments to estimate perceived colour-differences (Exp. II). 
and the standard illuminant $\mathrm{A}$ by three incandescent lamps, of the same kind as in Experiment I, requlated at $2856 \mathrm{~K}$ as in Experiment I.

This change in the illuminating conditions has been made for the reason that the optical system used for simulating the daylight $\mathrm{D}_{65}$ in Experiment I was troublesome in maintenance where experiments had to be conducted frequently. Replacing with an illuminating apparatus which is easier to operate has made visual experiments easier to conduct with more stability.

In order to examine the effects of this change in the illuminating conditions on the estimation of colour-differences, a comparison was made of the colour-differences by the ratio estimation method under the two illuminants. The results indicated a total absence of any adverse effect.

Male students and others of normal colour vision were employed as observers, but the group used in Experiment I was different from that in Experiment II as the two experiments were carried out in different years.

In the experiments for evaluation of colourdifferences, the observers adapted themselves to the illuminant for a few minutes before the start. Although no restriction was placed on the time for evaluation, the time required for evaluating, for example, 33 pairs of colour chips of $5 \mathrm{Y}$ was 20 minutes or so on the average.

\section{Changes in colour-differences owing to changes in Illuminant}

\subsection{Changes in perceived colour-differences}

The numerical values reported by the observers for pairs of colour chips are the values as judged multiplied by a factor of 10 . If the average is designated as $\overline{\mathrm{P}}$, the perceived colourdifferences relative to the standard pair of colour chips can be expressed as $\overline{\mathrm{P}} / 10$.

Figs. 4 (a) and 4 (b) give, for each hue, the correlation diagrams of the relative values of perceived colour-differences under the standard illuminant $A$ to those under the daylight $D_{65}$. The equations in these figures express regression lines and $\rho$ is the correlation coefficient. The correlation coefficients for all the hues are 0.93 or more, which shows the presence of high degrees of correlation. The gradients of the regression lines are 0.99 on the average, very

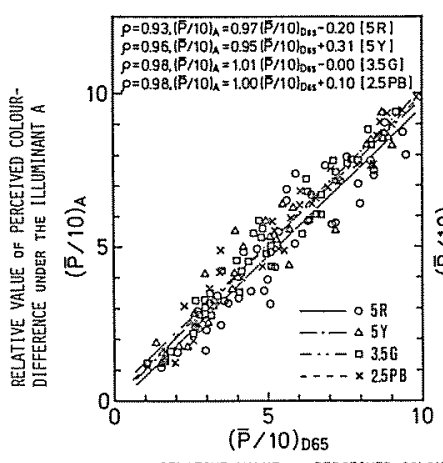

RELATIVE VALUE OF PERCEIVED COLOUR-DIFFEREICE UHDER THE DAYLIGHT D

(a)

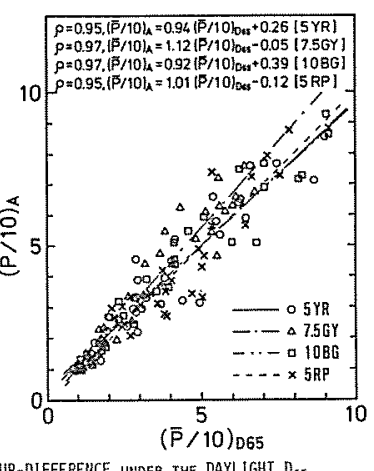

(b)
Fig. 4 Correlation diagrams of perceived colour-differences under the standard illuminant $A$ to those under the daylight $D_{65}$

close to 1.0 , except for $7.5 \mathrm{GY}$ whose gradient is 1.12 .

In order to study the effects of changes in chroma on the perceived colour-differences, the data were processed as follows.

Let us write the ratio of $(\overline{\mathrm{P}} / 10)_{\mathrm{A}}$ to $(\overline{\mathrm{P}} / 10)_{D_{65}}$ as $R_{N}$ were $(\overline{\mathrm{P}} / 10)_{A}$ is the perceived colour-differences under the standard illuminat $A$ and $(\bar{P} / 10)_{D_{65}}$ is those under the daylight $D_{65}$. Assuming that the ratio $R_{N}$ for an arbitrary pair of colour chips is constant over the range of chromas of the two colours in question, the averages of $R_{N}$ are calculated for all pairs of colour chips which cover the same chroma.

That is, in Fig. 2 which shows the combinations of pairs of colour chips and the colourdifferences, the values of colour-differences are substituted for $R_{N}$ and averaged vertically for each pair of adjoining colour chips. Fig. 5 shows the correspondence between the averages thus calculated and the averages of the chromas of adjoining colour chips.

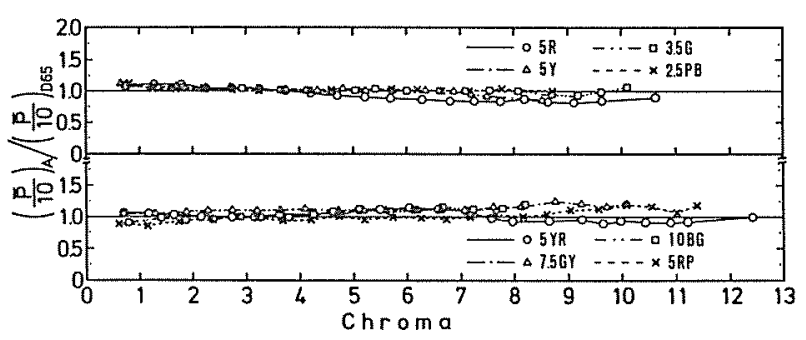

Fig. 5 Variations of the ratios of the relative values of perceived colourdifferences under the standard illuminant $A$ to those under the daylight $D_{65}$ in terms of chroma. 
In the case of $5 R$, the relative values of perceived colour-differences under the standard illuminant $\mathrm{A}$ tend to become slightly smaller than those under the daylight $\mathrm{D}_{65}$ as the chroma increases across a boundary of 4 or so. The same tendency is observed for $5 \mathrm{YR}$ and $5 \mathrm{Y}$.

On the contrary, with 7.5GY, 10BG, and $5 R P$, the relative values of perceived colourdifferences under the standard illuminant $A$ tend to become slightly larger than those under the daylight $\mathrm{D}_{65}$ with increasing chroma.

In connection with the constancy of colourdifferences, this finding needs to be investigated further by visual experiments. It is likely that, under an illuminant with a relatively high content of red components such as the standard illuminant $\mathrm{A}$, the eyes do not sharply perceive the colours from red to yellow owing to lowered sensitivity to red resulting from adaptation of the eye to the background light, reduced colour contrast with the background, and the like; hence, the perceived colour-differences under the standard illuminant $\mathrm{A}$ are rather more suppressed and smaller than those under the daylight $D_{65}$. The reverse may hold for the colours with higher contents of blue components.

The tendency mentioned above, however, is not very pronounced. Considering the high degrees of correlation observed, it can be said that, as a whole, the relative values of the perceived colour-differences vary little with the illuminant and the constancy of the perceived colour-differences for different chromas holds as in the case of hue-differences.

\subsection{Changes in Colorimetric Colour- differences}

As in the case of the perceived colourdifferences, the correlation diagrams of the relative values of colorimetric colour-differences under the standard illuminant $\mathrm{A}$ and those under the daylight $\mathrm{D}_{65}$ in the CIE $\mathrm{L}^{*} \mathrm{u}^{*} \mathrm{v}^{*}$ and $\mathrm{L}^{*} \mathrm{a} * \mathrm{~b} *$ spaces are shown in Figs. 6 (a) $\sim($ d).

The correlation coefficients obtained point to the presence of an extremely good correlation for each hue and in each colorimetric space. The gradients of the regression lines are in the vicinity of 1.0 in each colorimetric space except for $7.5 \mathrm{GY}, 3.5 \mathrm{G}$, and $10 \mathrm{BG}$. This suggests that the change in illuminant little affects the relative
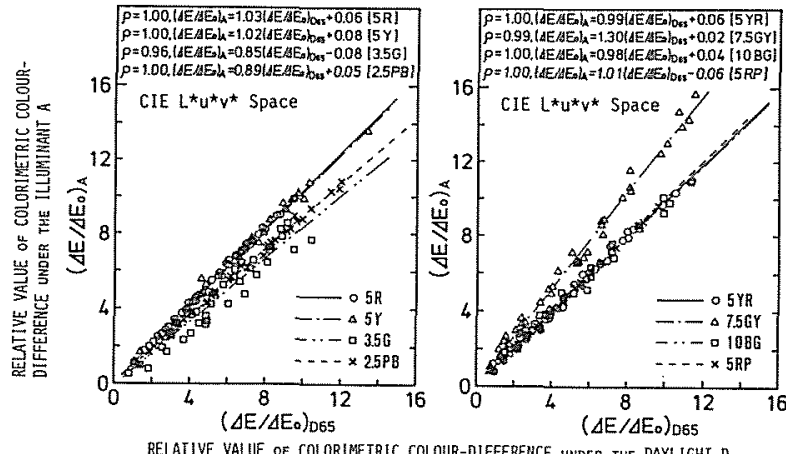

(a)

(b)
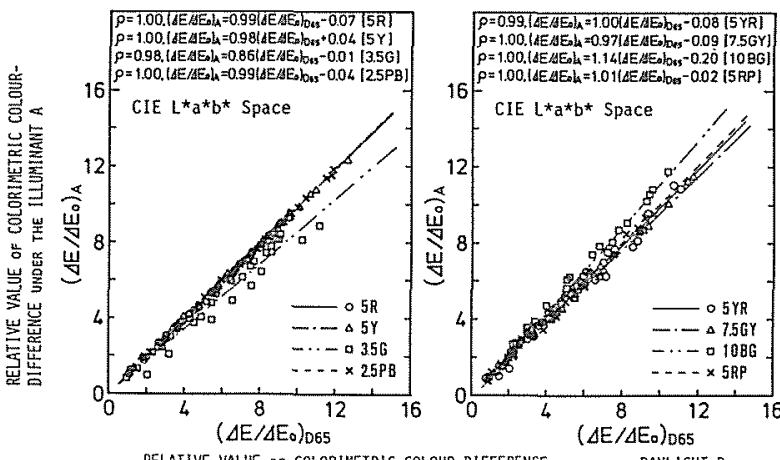

RELATIVE VALUE OF COLORINETRIC COLOUR-DIFFERENCE UIDER THE DAYLIGHI DS (c)

(d)

Fig. 6 Correlation diagrams of the relative values of colorimetric colour-differences under the standard illuminant $A$ to those under the daylight $D_{65}$.

(a), (b) CIE $L^{*} u^{*} v^{*}$ space
(c), (d) CIE $L^{*} a * b *$ space

values of colorimetric colour-differences. In the case of $3.5 \mathrm{G}$, the gradient is 0.85 in one colorimetric space and 0.86 in another, both less than 1.0 ; that is, the colorimetric colour-differences under the standard illuminant $\mathrm{A}$ are smaller than those under the daylight $\mathrm{D}_{65}$. On the other hand, the gradients for $7.5 \mathrm{GY}$ in the $\mathrm{L}^{*} \mathrm{u} \mathrm{v}^{*}$ space and $10 B G$ in the $L^{*} a^{*} b *$ space are greater than 1.0, indicating the reverse of what was found for $3.5 \mathrm{G}$. With respect to $7.5 \mathrm{GY}$, the gradient in the $\mathrm{L} * \mathrm{u} * \mathrm{v}^{*}$ space is 1.30 whereas that in the $\mathrm{L}^{*} \mathrm{a} * \mathrm{~b} *$ space is 0.97 , reflecting the difference in the characteristics of the colorimetric space. Except for some of the hues referred to above, however, the colorimetric colour-differences for different chromas in a given hue do not change appreciably when the illuminant is changed. This is a feature markedly different from that of the huedifferences. 


\section{Comparison of Perceived Colour- differences and Colorimetric Ones}

Figs. $7(a) \sim(h)$ depict the correlation diagrams of the relative values of perceived colourdifferences to those of colorimetric ones in the CIE $\mathrm{L}^{*} \mathrm{u} \mathrm{v}^{*}$ and CIE $\mathrm{L} * \mathrm{a} * \mathrm{~b} *$ spaces.

The correlation coefficients indicate the presence of high degrees of correlations as a whole: however, correlation coefficients of less than 0.9 are found for the following: $5 \mathrm{Y}$, $7.5 \mathrm{GY}$, and $5 \mathrm{RP}$ under the daylight $\mathrm{D}_{65}$ in the $\mathrm{L} * \mathrm{u} * \mathrm{~V}^{*}$ space, $5 \mathrm{R}$ and $5 \mathrm{Y}$ under the standard illuminant $\mathrm{A}$ in the $\mathrm{L}^{*} \mathrm{u}^{*} \mathrm{v} *$ space, $5 \mathrm{YR}, 5 \mathrm{Y}$, 7.5GY, and 10BG under the daylight $\mathrm{D}_{65}$ in the $\mathrm{L} * \mathrm{a} * \mathrm{~b} *$ space, and $5 \mathrm{YR}, 5 \mathrm{Y}$, and 7.5GY under the standard illuminant $\mathrm{A}$ in the $\mathrm{L} * \mathrm{a} * \mathrm{~b} *$ space. In each space and under each illuminant, a somewhat lower degree of correlation is observed near those hues which contain Y components.
Also, the gradient of regression line generally tends to be smaller for hues containing $\mathrm{Y}$ components in either space. This means that the perceived colour-differences are smaller than the colorimetric ones, which is not desirable from the standpoint of uniformity of the whole space. When these considerations are put together, the perceived colour-differences and the colorimetric ones do not show a good correspondence in the vicinity of those hues.

In particular, $7.5 \mathrm{GY}$ gives gradients of 0.5 or so in both spaces and under both illuminants, much smaller than those for ohter hues, suggesting a considerable distortion of the colorimetric space. However, a too excessive quantitative deviation from the rest seems to call for further studies on this particular hue.

The variations of the ratios of the perceived colour-differences to the colorimetric ones, or the perceived colour-differences per unit colori-

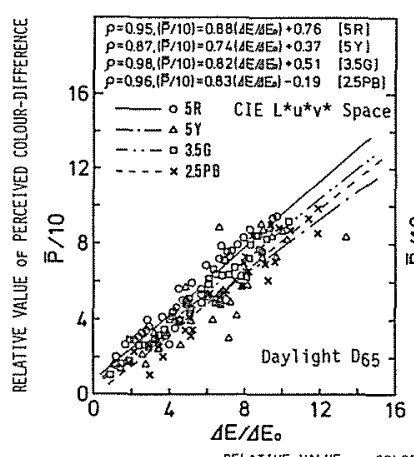

(a)

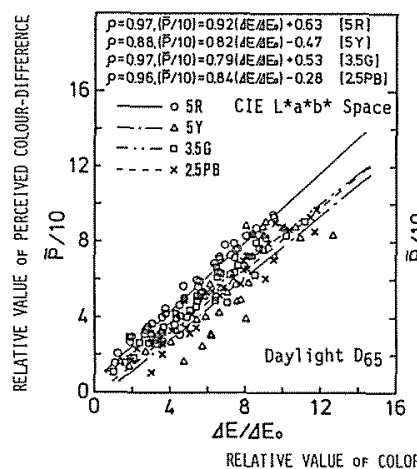

(e)

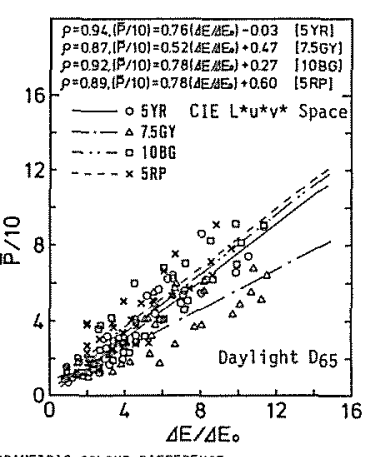

(b)

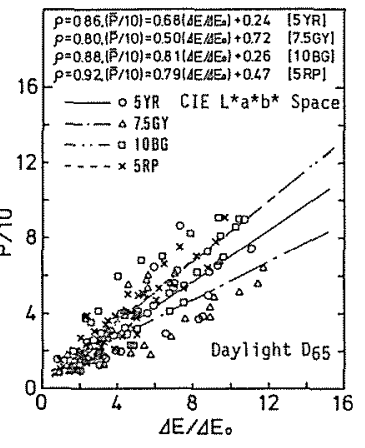

(f)

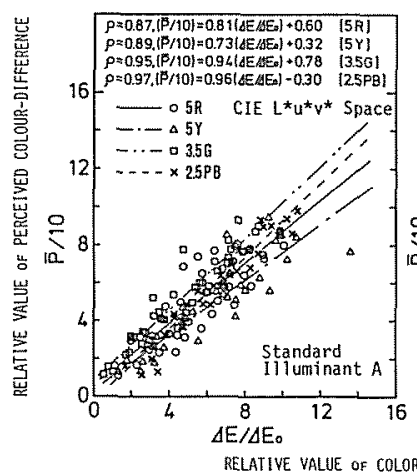

(c)

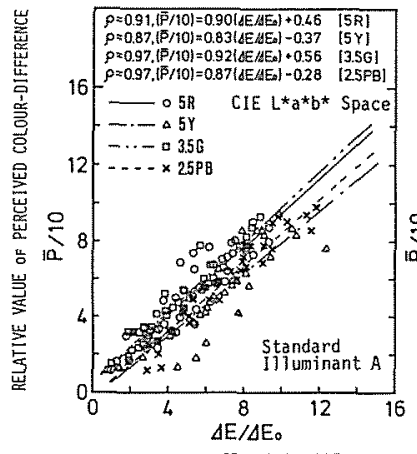

(g)

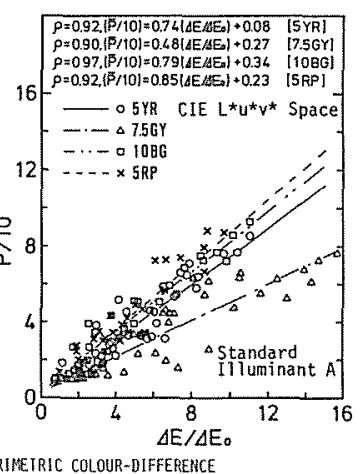

(d)

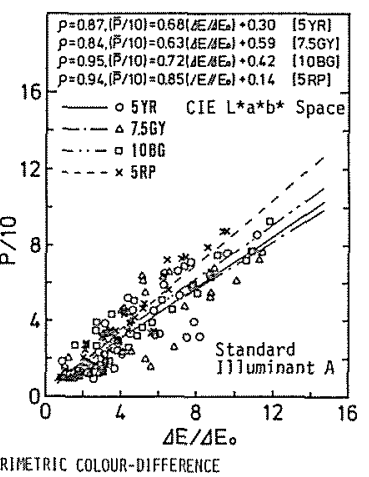

(h)

Fig. 7 Correlation diagrams of the relative values of perceived colour-differences to those of colorimetric ones.

(a), (b) CIE $L^{*} u^{*} v^{*}$ space (under the daylight $D_{65}$ ).

(e), (f) CIE $L * a * b *$ space (under the daylight $D_{65}$ ). (c), (d) CIE $L * u * v^{*}$ space (under the illuminant A).

(g), (h) CIE $L^{*} a^{*} b^{*}$ space (under the illuminant $A$ ). 
metric one $\mathrm{R}=(\overline{\mathrm{P}} / 10) /\left(\Delta E / \Delta E_{o}\right)$, in terms of chroma are shown in Fig. $8(\mathrm{a}) \sim(\mathrm{d})$ according to the same procedure as used in Section 4.1.

With any of 5R, 5YR, 7.5GY, 10BG, and $5 R P$, the perceived colour-differences per unit colorimetric ones tend to become smaller as the chroma increases regardless of the space or the illuminant. With $5 \mathrm{R}$, this tendency is distinctly noticeable under the standard illuminant $\mathrm{A}$, but

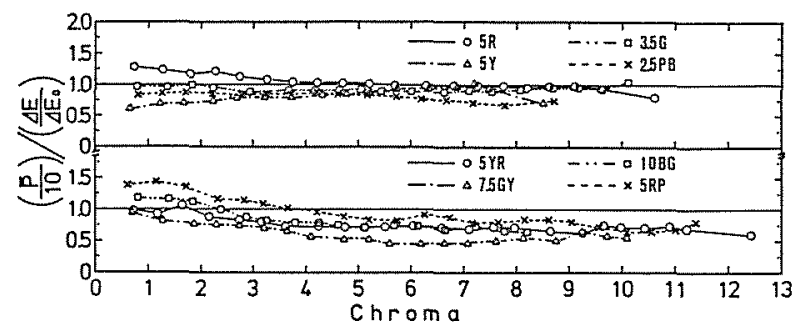

(a) CIE L* $u^{*} v^{*}$ Space (Daylight $D_{65}$ )

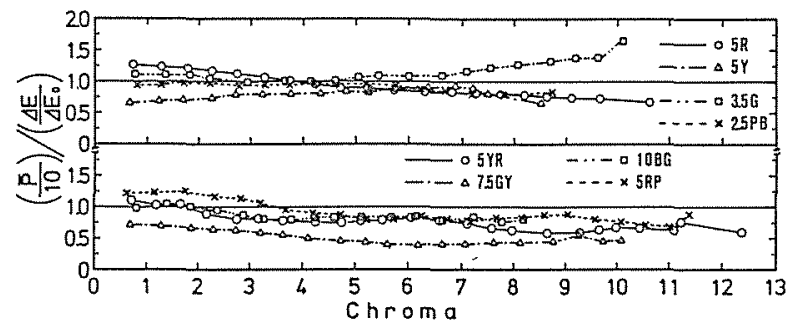

(b) CIE $L^{*} u^{*} \mathrm{~V}^{\star}$ Space (Standard Illuminant A)

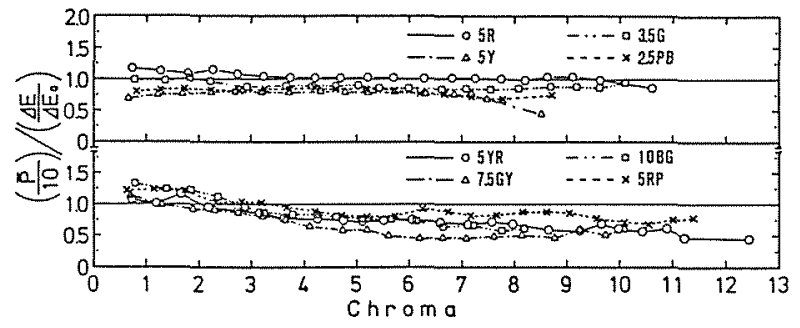

(c) CIE L*a*b* Space (Daylight D65)

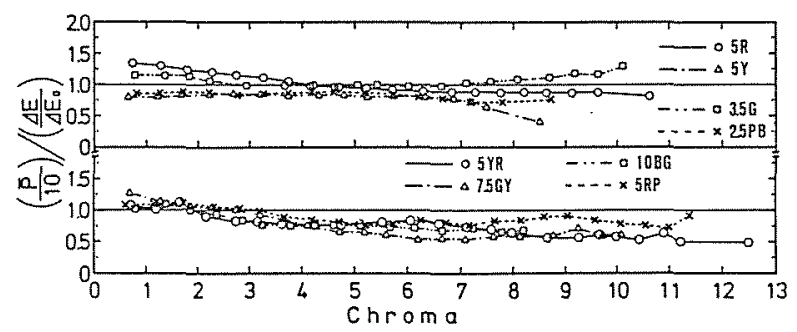

(d) CIE $L^{\star} a^{\star} b^{\star}$ Space (Standard Illuminant A)

Fig. 8 Variations of perceived colourdifferences per unit colorimetric one in terms of chroma.
(a) CIE $L^{*} u^{*} v^{*}$ space (under the daylight $D_{65}$ ).
(b) CIE $L^{*} u^{*} v^{*}$ space (under the illuminant $A$ ).
(c) CIE $L * a * b *$ space (under the daylight $D_{65}$ ).
(d) CIE $L * a * b *$ space (under the illuminant $A$ ).

not under the daylight $D_{65}$, and the differences attributable to the illuminant are large at high chromas. This suggests that, in the colorimetric spaces, there has not been sufficient compensation matching the chromatic adaptation to the red components of the illuminant.

For $5 \mathrm{Y}$, the colorimetric colour-differences are generally larger than the perceived ones and this tendency is more pronounced at lower chromas in the $\mathrm{L}^{*} \mathrm{u}^{*} \mathrm{v}^{*}$ space. A further study will be required on this point.

The characteristics of $3.5 \mathrm{G}$ under the standard illuminant $A$ in the $L^{*} u^{*} v^{*}$ space are different from those of other hues in that the colorimetric colour-differences are smaller than the perceived ones at higher chromas; the compensation matching the chromatic adaptation to the red and green components of the illuminant is insufficient in the $\mathrm{L}^{*} \mathrm{u}^{*} \mathrm{v}^{*}$ space and the degree of compensation is reflected here.

In order to study the perceived colourdifferences per unit colorimetric ones from the

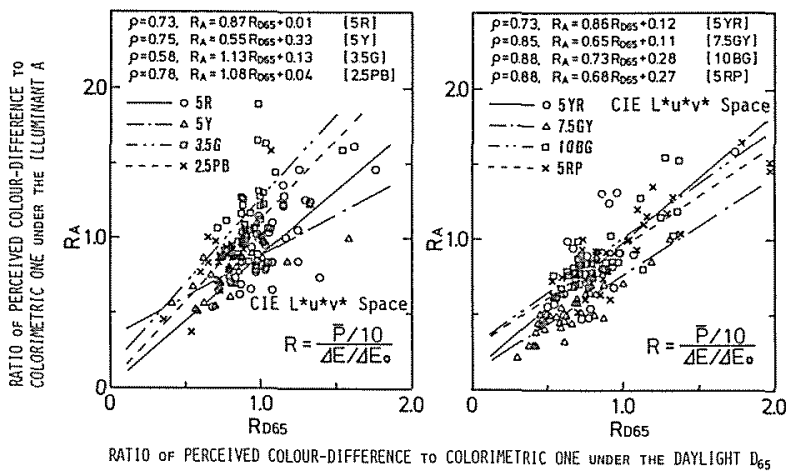

(a)

(b)

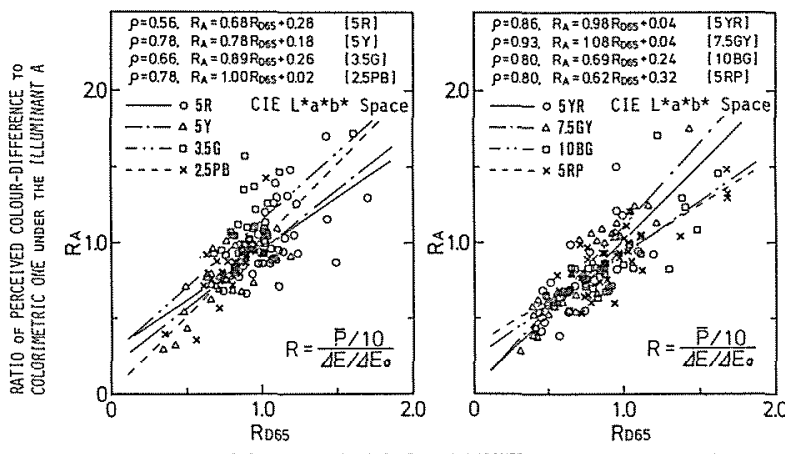

RATIO OF PERCEIVED COLOUR-DIFFEREMCE to COLORIAETRIC OHE UaDER THE DAYLIGHT D (c)

(d)

Fig. 9 Correlation diagrams of perceived colour-differences per unit colorimetric one under the standard illuminant $A$ to those under the daylight $D_{65}$.

(a), (b) CIE $L^{*} u^{*} v^{*}$ space

(c), (d) $C I E L * a * b *$ space 
viewpoint of compensation for chromatic adaptation, the correlation diagrams of the values under the standard illuminant $\mathrm{A}$ to those under the daylight $D_{65}$ are shown in Fig. 9(a) (d). A poor correspondence from the viewpoint of chromatic adaptation is observed for the perceived colour-differences per unit colorimetric one under different illuminants in the cases of $3.5 \mathrm{G}$ in both spaces and $5 \mathrm{R}$ in the $\mathrm{L} * \mathrm{a} * \mathrm{~b} *$ space. With $7.5 \mathrm{GY}$ and $5 \mathrm{Y}$ in the $\mathrm{L}^{*} \mathrm{u}^{*} \mathrm{v}^{*}$ space and $5 \mathrm{RP}$ in the $\mathrm{L}^{*} \mathrm{a} * \mathrm{~b} *$ space, the correlation coefficients are reasonably good but the gradients appear smaller. This suggests that the perceived colour-differences are relatively greater than the colorimetric ones under the daylight $\mathrm{D}_{65}$ and the reverse holds under the standard illuminant A near these hues.

\section{Conclusions}

A study was made on the correspondence between the perceived colour-differences and the colorimetric ones under the standard illuminant $\mathrm{A}$ and the daylight $\mathrm{D}_{65}$ for chromadifferences. The results are summarized as follows.

(1) Good correlations are observed between the perceived chroma-differences under the daylight $\mathrm{D}_{65}$ and those under the standard illuminant A. Relative values of perceived colour-differences change little ever when the illuminant is changed. The constancy of the perceived colour-differences holds as well as in the case of hue-differences.

(2) Unlike the hue-differences, the colorimetric colour-differences show considerably high degrees of correlation in both spaces when the illuminant is changed. However, insufficient compensation for chromatic adaptation is noted for $3.5 \mathrm{G}$.

(3) The hues of $5 \mathrm{Y}$ and $7.5 \mathrm{GY}$ show a slightly lower degree of correspondence between the perceived colour-differences and the colorimetric ones than other hues. This finding agrees with what the industries often point out as problems in colour control.

(4) In each colorimetric space and under each illuminant, the perceived colour-differences tend to become relatively smaller than the colorimetric ones, except for $5 \mathrm{Y}$ and $3.5 \mathrm{G}$, as the chroma increases.

(5) With 3.5G under the standard illuminant
A, the perceived colour-differences tend to become larger than the colorimetric ones as the chroma increases. This tendency is particularly pronounced in the $\mathrm{L}^{*} \mathrm{u} * \mathrm{v} *$ space.

(6) When the illuminant is changed, the perceived colour-differences per unit colorimetric ones show a low degree of correlation for $3.5 \mathrm{G}$ in both spaces and for $5 \mathrm{R}$ in the $\mathrm{L} * \mathrm{a} * \mathrm{~b}^{*}$ space.

Further visual experiments will be needed to draw any more conclusions than those described above.

It is being planned to carry out similar visual experiments by using standard and comparison pairs of colour chips chosen on a standpoint different from that of the present study, for example, to compare chroma-differences in different hues by choosing achromatic colourdifferences as a common standard, and to investigate at low chroma by using a group of colour chips with the chroma changing continuously in one hue and the hue on the opposite side through the achromatic colour in a colorimetric colour space. Also, a study on the correspondence of perceived chroma-differences with the Munsell colour-differences is planned.

\section{References}

(1) "Official Recommendations on Uniform Color Spaces, Color-Difference Equations, and Metric Color Terms", Supplement No. 2 to CIE Publication No. 15, Colorimetry (E-1.3.1) 1971 (1976).

(2) Ikeda, K., Nakayama, M. and Obara, K.: "Perceived colour-differences under the illuminant A and the CIE daylight", Papers of Technical Meeting of VISUAL INFORMATION, IEE of Japan, VIN-77-9 (1977) 9-1 (in Japanese).

(3) Ikeda, K., Nakayama, M. and Obara, K.: "Comparison between perceived colour-differences and colorimetric ones of colour chips illuminated by standard illuminant $\mathrm{A}$ and by daylight illuminant $\mathrm{D}_{65}$ in terms of ratio estimation mathod", J. Color Sci. Assoc. of Japan, 3-1 (1978) 12 (in Japanese).

(4) Ikeda, K., Nakayama, M. and Obara, K.: "Comparison of perceived colour-differences of colour chips with their colorimetric ones in the CIE $1976 \mathrm{~L}^{*} \mathrm{u}^{*} \mathrm{v}^{*}$ and the CIE $1976 \mathrm{~L}^{*} \mathrm{a}^{*} \mathrm{~b}$ * uniform colour spaces", CIE Publication No. 50 (1980) 83.

(5) Ikeda, K., Nakayama, M. and Obara, K.: "The correction of the colour adaptation in the CIE uniform colour spaces," Papers of Technical Meeting on LIGHT APPLICATION AND 
VISUAL SYSTEM, IEE of Japan, LAV-80-22 (1980) 42 (in Japanese).

(6) Ikeda, K., Nakayama, M. and Obara, K.: "Relation between colorimetric colour-differences and perceived ones for saturated colour chips with constant value and chroma", J. Light \& Vis. Env., 6-1 (1982) 31.

(7) Ikeda, K., Nakayama, M. and Obara, K.: “Design a light source with arbitrary spectral energy distribution and simulation of CIE Standard Daylight Illuminants for colorimetry", ACTA CHROMATICA, 3-2 (1977) 64.

(8) Hunt, R.W.G.: Circular of CIE Technical Comitee 1.3 (Colorimetry), (1st April 1976).

Received 21 July 1986; Devision Received 5 Jan. 1987 